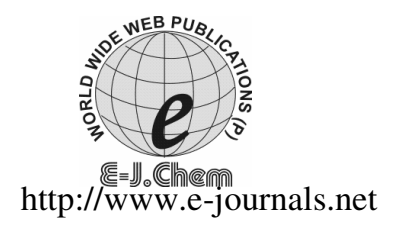

\title{
An Efficient Solvent-Free Protocol for the Synthesis of 1-Amidoalkyl-2-naphthols using Silica-Supported Molybdatophosphoric Acid
}

\author{
ABDOLKARIM ZARE ${ }^{{ }^{*}}$, ALIREZA HASANINEJAD ${ }^{\#}$, ESMAEL ROSTAMI $^{\S}$, \\ AHMAD REZA MOOSAVI-ZARE, NASRIN PISHAHANG ${ }^{\S}$, \\ MEHRNOOSH ROSHANKAR $^{\S}$, FATEMEH KHEDRI $^{\S}$ and MAASOOMEH KHEDRI ${ }^{\S}$
}

${ }^{\S}$ Department of Chemistry, Payame Noor University (PNU), Iran.

\#Department of Chemistry,

Faculty of Sciences, Persian Gulf University, Bushehr 75169, Iran.

Faculty of Chemistry,

Bu-Ali Sina University, P. O. Box 4135, Hamadan 6517838683, Iran.

abdolkarimzare@yahoo.com

Received 10 November 2009; Accepted 5 January 2010

\begin{abstract}
A highly efficient, green and simple solvent-free method for the synthesis of 1-amidoalkyl-2-naphthols via one-pot multi-components condensation of 2-naphthol, aromatic aldehydes and amides in the presence of catalytic amount of silica-supported molybdatophosphoric acid $\left(\mathrm{H}_{3} \mathrm{PMo}_{12} \mathrm{O}_{40} \cdot \mathrm{xH}_{2} \mathrm{O} / \mathrm{SiO}_{2}\right.$, $3.17 \mathrm{~mol} \%$ ) is described. The reactions proceed rapidly and the title compounds are produced in high to excellent yields.
\end{abstract}

Keywords: 1-Amidoalkyl-2-naphthol, Molybdatophosphoric acid, Heteropolyacid, Solvent-free, Multi-components reaction, 2-Naphthol.

\section{Introduction}

1-Amidoalkyl-2-naphthol derivatives are of importance because they can be easily converted to the important biologically active compounds, 1-aminoalkyl-2-naphthols, by amide hydrolysis reaction. The hypotensive and bradycardiac properties have been reported for this class of compounds ${ }^{1,2}$. 1-Amidoalkyl-2-naphthols can be also converted to 1,3-oxazine derivatives ${ }^{3}$. 1,3-Oxazines have potentially different biological activities including antibiotic ${ }^{4}$, antitumor ${ }^{5}$, analgesic ${ }^{6}$, anticonvulsant ${ }^{7}$, antipsychotic ${ }^{8}$, antimalarial ${ }^{9}$, antianginal $^{10}$, antihypertensive ${ }^{11}$ and antirheumatic properties ${ }^{12}$. One-pot multi-components condensation of 2-naphthol, aromatic aldehydes and amide derivatives or acetonitrile has been used as a practical synthetic routes toward 1-amidoalkyl-2-naphthols ${ }^{13-22}$. Several Lewis and Brønsted acids have been applied for this transformation including $\mathrm{Ce}\left(\mathrm{SO}_{4}\right)_{2}{ }^{13}$, 
Montmorillonite $\mathrm{K}_{10}{ }^{14}$, iodine ${ }^{15}$, cation-exchanged resins ${ }^{16}, \mathrm{NaHSO}_{4} \cdot \mathrm{H}_{2} \mathrm{O}^{17}, \mathrm{Fe}\left(\mathrm{HSO}_{4}\right)_{3}{ }^{18}$, sulfamic acid/ultrasound ${ }^{19}, \mathrm{HClO}_{4} / \mathrm{SiO}_{2}{ }^{20}$, cyanuric chloride ${ }^{21}$ and $\mathrm{K}_{5} \mathrm{CoW}_{12} \mathrm{O}_{40} \cdot 3 \mathrm{H}_{2} \mathrm{O}^{22}$. However, many of the reported methods suffer from one or more of the following drawbacks: (i) low product yield, (ii) prolonged reaction time, (iii) the use of large amount of reagent, (iv) the use of toxic reagents and (v) incompatibility with the green chemistry protocols. Therefore, search for finding a protocol for the synthesis of 1-aminoalkyl-2naphthols that are not associated with the above disadvantages is still relevant.

Heteropolyacids are important catalysts in industries for fine organic synthetic processes related with fine chemicals such as synthesis of antioxidants, medicinal preparations, vitamins and biologically active substances ${ }^{23}$. They are more active catalysts than conventional inorganic and organic acids for a variety of organic reactions ${ }^{24-31}$. Among heteropolyacids, molybdatophosphoric acid $\left(\mathrm{H}_{3} \mathrm{PMo}_{12} \mathrm{O}_{40} \cdot \mathrm{XH}_{2} \mathrm{O}\right)$ is a good promoter due to its high acid strengths, thermal stabilities, low reducibility and atom economy ${ }^{24,28-31}$.

Recently, the use of catalysts and reagents supported on solid supports under solventfree conditions has been developed because such reagents not only cause to simplify the purification processes but also help to prevent the releasing of toxic reaction residues into the environment ${ }^{32-42}$. Moreover, due to moisture sensitivity of some reagents; application of them in organic reactions is difficult. This problem can be solved by supporting of them on solid supports ${ }^{32-42}$. Handling of solid-supported reagents is also easy. Silica gel is one of the most interesting solid supports and is inexpensive, reusable, commercially available and environmentally benign which has been used in various organic transformations ${ }^{36-42}$. Consequently, it is noteworthy that the combination of safe supported-catalysis with the use of solvent-free technique represents a suitable way toward the so-called "ideal synthesis" $32-42$.

In this paper, we report a new, efficient and simple method for the synthesis of 1-aminoalkyl-2-naphthols from 2-naphthol, aromatic aldehydes and amides in the presence of $\mathrm{H}_{3} \mathrm{PMo}_{12} \mathrm{O}_{40} \cdot \mathrm{xH}_{2} \mathrm{O} / \mathrm{SiO}_{2}$ as a green catalytic system under solvent-free conditions (Scheme 1). It is worth noting that this method has none of the above-mentioned disadvantages at all.

\section{Experimental}

All chemicals were purchased from Merck or Fluka Chemical Companies. Silica gel 60, 0.063-0.200 mm (7-230 mesh ASTM) was applied as support. The structures of known compounds were identified by comparison of their melting points and spectral data with those in the authentic samples. The ${ }^{1} \mathrm{H}$ NMR $(250$ or $300 \mathrm{MHz})$ and ${ }^{13} \mathrm{C}$ NMR $(62.5$ or $75 \mathrm{MHz})$ were run on a Bruker Avance DPX-250 FT-NMR spectrometer ( $\delta$ in ppm). Microanalyses were performed on a Perkin-Elmer 240-B microanalyzer. Melting points were recorded on a Büchi B-545 apparatus in open capillary tubes.

Procedure for the preparation of $\mathrm{H}_{3} \mathrm{PMo}_{12} \mathrm{O}_{40} \cdot \mathrm{xH}_{2} \mathrm{O} / \mathrm{SiO}_{2}(33 \% \mathrm{w} / \mathrm{w})$ catalytic system A mixture of $\mathrm{H}_{3} \mathrm{PMo}_{12} \mathrm{O}_{40} \cdot \mathrm{xH}_{2} \mathrm{O}(1 \mathrm{~g})$ and $\mathrm{SiO}_{2}(2 \mathrm{~g})$ was ground vigorously to give $\mathrm{H}_{3} \mathrm{PMo}_{12} \mathrm{O}_{40} \cdot \mathrm{xH}_{2} \mathrm{O} / \mathrm{SiO}_{2}$ catalytic system as a yellow powder $(3 \mathrm{~g})$.

\section{General procedure for the synthesis of 1-amidoalkyl-2-naphthol derivatives}

To a well-ground mixture of 2-naphthol (2 mmol, $0.288 \mathrm{~g})$, amide $(2.4 \mathrm{mmol})$ and $\mathrm{H}_{3} \mathrm{PMo}_{12} \mathrm{O}_{40} \cdot \mathrm{xH}_{2} \mathrm{O} / \mathrm{SiO}_{2}(0.350 \mathrm{~g}, 3.17 \mathrm{~mol} \%)$ in a $10 \mathrm{~mL}$ round-bottomed flask connected to a reflux condenser, was added aldehyde $(2 \mathrm{mmol})$ and the resulting mixture was stirred in an oil-bath $\left(120^{\circ} \mathrm{C}\right)$ for the appropriate time. After completion of the reaction, as monitored by TLC, the reaction mixture was cooled to room temperature, and was added to a column chromatography on silica gel and eluted with EtOAc/n-hexane (1/2) to give pure product. 
General procedure for the condensation of 2-naphthol with terephthalaldehyde and acetamide leading to 1-amidoalkyl-2-naphthol and bis-1-amidoalkyl-2-naphthol

A well-ground mixture of 2-naphthol (4 mmol, $0.576 \mathrm{~g})$, acetamide (4.8 mmol, $0.284 \mathrm{~g})$, silica-supported $\mathrm{H}_{3} \mathrm{PMo}_{12} \mathrm{O}_{40} \cdot \mathrm{xH}_{2} \mathrm{O}(0.700 \mathrm{~g}, 6.34 \mathrm{~mol} \%)$ and terephthalaldehyde $(2 \mathrm{mmol}, 0.268 \mathrm{~g}$ ) in a $10 \mathrm{~mL}$ round-bottomed flask connected to a reflux condenser was stirred in an oil-bath $\left(120{ }^{\circ} \mathrm{C}\right)$ for $30 \mathrm{~min}$. Afterward, the reaction mixture was cooled to room temperature and warm aqueous ethanol $(15 \%, 20 \mathrm{~mL})$ was added to it and stirred for 5 min (1-amidoalkyl-2naphthol is soluble in warm aqueous ethanol, however, bis-1-amidoalkyl-2-naphthol is insoluble in this solvent). During this time, the crude 1-amidoalkyl-2-naphthol was dissolved in the ethanol and pure bis-1-amidoalkyl-2-naphthol was remained; thus, two products were easily separated by filtration. Then, the crude 1-amidoalkyl-2-naphthol was purified by column chromatography on silica gel eluted with EtOAc/n-hexane (1/2).

\section{Selected spectral data of the products}

\section{$N$-[(2-Hydroxynaphthalen-1-yl)(phenyl)methyl)]acetamide (1)}

White solid; m.p. 239-240 ${ }^{\circ} \mathrm{C}$ (lit. ${ }^{13} 241-243{ }^{\circ} \mathrm{C}$ ); ${ }^{1} \mathrm{H}$ NMR (DMSO-d 6 , $250 \mathrm{MHz}$ ): $\delta 2.06$ $(\mathrm{s}, 3 \mathrm{H}), 7.01-7.20(\mathrm{~m}, 9 \mathrm{H}), 7.65-7.73(\mathrm{~m}, 3 \mathrm{H}), 8.11(\mathrm{~d}, J=7.7 \mathrm{~Hz}, 1 \mathrm{H}), 9.69(\mathrm{~s}, 1 \mathrm{H}) ;{ }^{13} \mathrm{C}$ NMR (DMSO-d 6 , 62.5 MHz): $\delta 23.5,41.3,118.8,120.2,122.0,123.9,124.9,125.7,127.6$, 128.1, 128.3, 128.5, 128.6, 134.2, 144.0, 152.6, 169.6; Anal. calcd. for $\mathrm{C}_{19} \mathrm{H}_{17} \mathrm{NO}_{2}$ : C, 78.33 ; H, 5.88; N, 4.81. Found: C, 78.54; H, 6.01; N, 4.65.

\section{$\mathrm{N}$-[(2-Hydroxynaphthalen-1-yl)(3-nitrophenyl)methyl)]acetamide (8)}

Pale yellow solid; m.p. $238-240{ }^{\circ} \mathrm{C}$ (lit. ${ }^{16} 236-237{ }^{\circ} \mathrm{C}$ ); ${ }^{1} \mathrm{H}$ NMR (DMSO-d 6 , $250 \mathrm{MHz}$ ): $\delta 2.06(\mathrm{~s}, 3 \mathrm{H}), 7.15-7.49(\mathrm{~m}, 6 \mathrm{H}), 7.78-8.04(\mathrm{~m}, 5 \mathrm{H}), 8.54(\mathrm{~d}, J=8.1 \mathrm{~Hz}, 1 \mathrm{H}), 10.12(\mathrm{~s}, 1 \mathrm{H})$; ${ }^{13} \mathrm{C}$ NMR (DMSO-d 6 , 62.5 MHz): $\delta 23.3,48.1,118.1,118.7,120.5,122.3,123.8,125.7$, 127.3, 128.4, 129.1, 129.6, 130.8, 133.1, 134.1, 144.5, 148.7, 152.9, 169.8; Anal. calcd. for $\mathrm{C}_{19} \mathrm{H}_{16} \mathrm{~N}_{2} \mathrm{O}_{4}$ : C, 67.85; H, 4.79; N, 8.33. Found: C, 68.04; H, 4.68; N, 8.47.

$\mathrm{N}$-[(2-Hydroxynaphthalen-1-yl)(4-chlorophenyl)methyl)]acetamide (10)

Pale yellow solid; m.p. $220-222{ }^{\circ} \mathrm{C}$ (lit. ${ }^{13}{ }^{224-227}{ }^{\circ} \mathrm{C}$ ); ${ }^{1} \mathrm{H}$ NMR (DMSO-d 6 , $250 \mathrm{MHz}$ ): $\delta 2.07$ (s, 3H), $7.06(\mathrm{~m}, 2 \mathrm{H}), 7.14-7.24(\mathrm{~m}, 5 \mathrm{H}), 7.68-7.77(\mathrm{~m}, 3 \mathrm{H}), 7.98(\mathrm{~d}, J=7.4 \mathrm{~Hz}, 1 \mathrm{H}), 8.16$ $(\mathrm{d}, J=7.1 \mathrm{~Hz}, 1 \mathrm{H}), 9.90(\mathrm{~s}, 1 \mathrm{H}) ;{ }^{13} \mathrm{C}$ NMR (DMSO-d $\left.6,62.5 \mathrm{MHz}\right): \delta 23.2,47.6,118.8,119.8$, 122.1, 123.7, 125.8, 126.9, 127.4, 128.3, 128.6, 129.3, 129.9, 134.0, 143.4, 152.5, 169.8; Anal. calcd. for $\mathrm{C}_{19} \mathrm{H}_{16} \mathrm{ClNO}_{2}$ : C, 70.05; H, 4.95; N, 4.30. Found: C, 69.78; H, 4.79; N, 4.42.

$\mathrm{N}$-[(4-Chloro-phenyl)-(2-hydroxy-naphthalen-1-yl)-methyl]nicotinamide (16)

White solid; m.p. 206-209 ${ }^{\circ} \mathrm{C} ;{ }^{1} \mathrm{H}$ NMR (DMSO-d 6 , $\left.300 \mathrm{MHz}\right): \delta$ 7.27-7.50 (m, 9H), 7.83 $(\mathrm{d}, J=8.7 \mathrm{~Hz}, 2 \mathrm{H}), 8.10(\mathrm{~d}, J=8.4 \mathrm{~Hz}, 1 \mathrm{H}), 8.27(\mathrm{~d}, J=7.8 \mathrm{~Hz}, 1 \mathrm{H}), 8.71(\mathrm{~d}, J=4.4 \mathrm{~Hz}$, 1H), $9.12(\mathrm{~s}, 1 \mathrm{H}), 9.35(\mathrm{~d}, J=7.6 \mathrm{~Hz}, 1 \mathrm{H}), 10.38(\mathrm{~s}, 1 \mathrm{H}) ;{ }^{13} \mathrm{C}$ NMR (DMSO-d $\left.6,75 \mathrm{MHz}\right): \delta$ 49.4, 118.2, 119.1, 123.1, 123.5, 123.9, 127.2, 128.6, 128.9, 129.2, 130.1, 130.4, 131.7, 132.8, 135.8, 141.2, 149.1, 152.4, 153.9, 165.4; MS $\mathrm{m} / z: 388.3\left(\mathrm{M}^{+}\right)$; Anal. calcd. for $\mathrm{C}_{23} \mathrm{H}_{17} \mathrm{ClN}_{2} \mathrm{O}_{2}$ : C, 71.04; H, 4.41; N, 7.20. Found: C, 71.32; H, 4.28; N, 7.36.

$\mathrm{N}$-[(4-Formylphenyl)(2-hydroxynaphthalen-1-yl)methyl]acetamide (17)

Pale yellow solid; m.p. $237-240{ }^{\circ} \mathrm{C}$; ${ }^{1} \mathrm{H}$ NMR (DMSO-d 6 , $300 \mathrm{MHz}$ ): $\delta 2.02$ (s, 3H), 6.91-7.39 $(\mathrm{m}, 6 \mathrm{H}), 7.79-7.82(\mathrm{~m}, 4 \mathrm{H}), 8.41(\mathrm{~d}, J=6.6 \mathrm{~Hz}, 1 \mathrm{H}), 8.56(\mathrm{~d}, J=7.6 \mathrm{~Hz}, 1 \mathrm{H}), 9.93(\mathrm{~s}, 1 \mathrm{H})$, $10.10(\mathrm{~s}, 1 \mathrm{H}) ;{ }^{13} \mathrm{C}$ NMR (DMSO-d $\left.{ }_{6}, 75 \mathrm{MHz}\right): \delta 23.0,48.4,118.6,118.8,122.9,123.5,126.3$, 127.1, 128.9, 129.1, 129.9, 130.1, 132.7, 134.9, 150.6, 153.7, 170.1, 193.1; MS m/z: $319.2\left(\mathrm{M}^{+}\right)$; Anal. calcd. for $\mathrm{C}_{20} \mathrm{H}_{17} \mathrm{NO}_{3}$ : C, 75.22; H, 5.37; N, 4.39. Found: C, 75.01; H, 5.25; N, 4.53. 
N-[\{4-[Acetylamino-(2-hydroxy-naphthalen-1-yl)-methyl]-phenyl]-(2-hydroxy-naphthalen1-yl)-methyl]acetamide (18)

White solid; m.p. 277-279 ${ }^{\circ} \mathrm{C} ;{ }^{1} \mathrm{H}$ NMR (DMSO-d 6 , $\left.300 \mathrm{MHz}\right): \delta 2.01(\mathrm{~s}, 6 \mathrm{H}), 7.17-7.39$ $(\mathrm{m}, 12 \mathrm{H}), 7.77-7.93(\mathrm{~m}, 6 \mathrm{H}), 8.53(\mathrm{~d}, J=8.2 \mathrm{~Hz}, 2 \mathrm{H}), 10.09(\mathrm{~s}, 2 \mathrm{H}) ;{ }^{13} \mathrm{C}$ NMR (DMSO-d ${ }_{6}$, $75 \mathrm{MHz}): \delta 23.1,48.2,118.9,119.2,122.8,126.3,126.8,128.9,129.0,129.6,132.7,140.8$, 140.9, 153.6, 169.7; MS $m / z$ : $504.5\left(\mathrm{M}^{+}\right)$; Anal. calcd. for $\mathrm{C}_{32} \mathrm{H}_{28} \mathrm{~N}_{2} \mathrm{O}_{4}$ : C, 76.17; H, 5.59; N, 5.55. Found: C, 75.86; H, 5.43; N, 5.73.

\section{Results and Discussion}

To optimize the reaction conditions, at first we selected the synthesis of $N$-((2-hydroxynaphthalen1-yl)(phenyl)methyl)acetamide (1) as a model reaction (Scheme 1); thus, to a well-ground mixture of 2-naphthol $(2 \mathrm{mmol})$, acetamide $(2.4 \mathrm{mmol})$ and molybdatophosphoric acid (0.117 g, $3.17 \mathrm{~mol} \%)$ was added benzaldehyde $(2 \mathrm{mmol})$ and the resulting mixture was stirred in an oil-bath $\left(120^{\circ} \mathrm{C}\right)$ under solvent-free conditions.

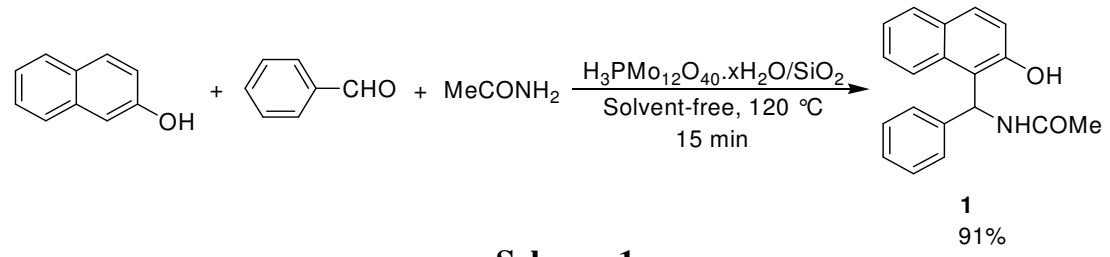

\section{Scheme 1}

However, in these conditions, a highly sticky reaction mixture was obtained and the product was obtained in $79 \%$ yield after 15 min. Increasing the reaction time or the temperature didn't improve the yield. The synthesis of 1-amidoalkyl-2-naphthol 1 was also examined in different solvents including DMF, DMSO, NMP, HMPTA, THF, EtOH and $\mathrm{EtOH} / \mathrm{H}_{2} \mathrm{O}(1 / 1, \mathrm{v} / \mathrm{v})$; but, low yields $(34-65 \%)$ of the product were obtained in long reaction times $(2-4 \mathrm{~h})$ in the solution conditions. The yield increased to $91 \%$ when the reaction was carried out in the presence of silica-supported $\mathrm{H}_{3} \mathrm{PMo}_{12} \mathrm{O}_{40} \cdot \mathrm{xH}_{2} \mathrm{O}(33 \% \mathrm{w} / \mathrm{w})$ as catalyst under solvent-free conditions (Table 1, entry 3). To choose suitable amount of $\mathrm{H}_{3} \mathrm{PMo}_{12} \mathrm{O}_{40} \cdot \mathrm{xH}_{2} \mathrm{O} / \mathrm{SiO}_{2}$ as well as reaction temperature, the multi-components condensation of 2-naphthol ( $2 \mathrm{mmol})$, benzaldehyde $(2 \mathrm{mmol})$ and acetamide $(2.4 \mathrm{mmol})$ was tested using different amount of the catalytic system at range of $100-130{ }^{\circ} \mathrm{C}$ in the absence of solvent. The results are summarized in Table 1 . As it can be seen in Table 1, the reasonable results were obtained in the presence of $0.35 \mathrm{~g}(3.17 \mathrm{~mol} \%)$ of $\mathrm{H}_{3} \mathrm{PMo}_{12} \mathrm{O}_{40} \cdot \mathrm{xH}_{2} \mathrm{O} / \mathrm{SiO}_{2}$ at $120{ }^{\circ} \mathrm{C}$.

Table 1. The condensation of 2-naphthol $(2 \mathrm{mmol})$, benzaldehyde $(2 \mathrm{mmol})$ and acetamide $(2.4 \mathrm{mmol})$ using different amount of $\mathrm{H}_{3} \mathrm{PMo}_{12} \mathrm{O}_{40} \cdot \mathrm{xH}_{2} \mathrm{O} / \mathrm{SiO}_{2}(33 \% \mathrm{w} / \mathrm{w})$ at range of $100-130{ }^{\circ} \mathrm{C}$

\begin{tabular}{ccccc}
\hline Entry & Catalyst Amount, $\mathrm{g}$ & Temperature, ${ }^{\circ} \mathrm{C}$ & Time, min & Yield $^{\mathrm{a}}, \%$ \\
\hline 1 & $0.25(2.28 \mathrm{~mol} \%)$ & 120 & 30 & 68 \\
2 & $0.30(2.73 \mathrm{~mol} \%)$ & 120 & 20 & 85 \\
3 & $0.35(3.17 \mathrm{~mol} \%)$ & 120 & 15 & 91 \\
$4^{b}$ & $0.40(3.65 \mathrm{~mol} \%)$ & 120 & 15 & 91 \\
5 & $0.35(3.17 \mathrm{~mol} \%)$ & 100 & 40 & 60 \\
6 & $0.35(3.17 \mathrm{~mol} \%)$ & 110 & 25 & 77 \\
7 & $0.35(3.17 \mathrm{~mol} \%)$ & 130 & 15 & 90 \\
\hline
\end{tabular}

${ }^{a}$ Isolated yield. ${ }^{b}$ Increasing the amount of $\mathrm{H}_{3} \mathrm{PMo}_{12} \mathrm{O}_{40} \cdot \mathrm{xH}_{2} \mathrm{O} / \mathrm{SiO}_{2}$ didn't improve the reaction results. 
To assess generality and scope of the method, 2-naphthol was reacted with various aromatic aldehydes and amides. The results are displayed in Table 2. As it is shown in Table 2, using this method, all aldehydes including benzaldehyde as well as aromatic aldehydes possessing electron-withdrawing substituents, electron-releasing substituents or halogens on their aromatic rings afforded the desired 1-amidoalkyl-2-naphthols in high to excellent yields and in short reaction times (Table 2, compounds 1-13). The method was also successfully worked when benzamide or nicotinamide was used instead of acetamide in the reaction (Table 2, compounds 14-16).

Table 2. The Solvent-free synthesis of 1-aminoalkyl-2-naphthols from 2-naphthol, aromatic aldehydes and amides using $\mathrm{H}_{3} \mathrm{PMo}_{12} \mathrm{O}_{40} \cdot \mathrm{xH}_{2} \mathrm{O} / \mathrm{SiO}_{2}$ at $120{ }^{\circ} \mathrm{C}$

\begin{tabular}{cccc}
\hline Compound Number & Time, min & Yield $^{\mathrm{a}} \%$ & M.p. ${ }^{\circ} \mathrm{C}$ (Lit.) \\
$239-240$ \\
$(241-243)^{13}$
\end{tabular}




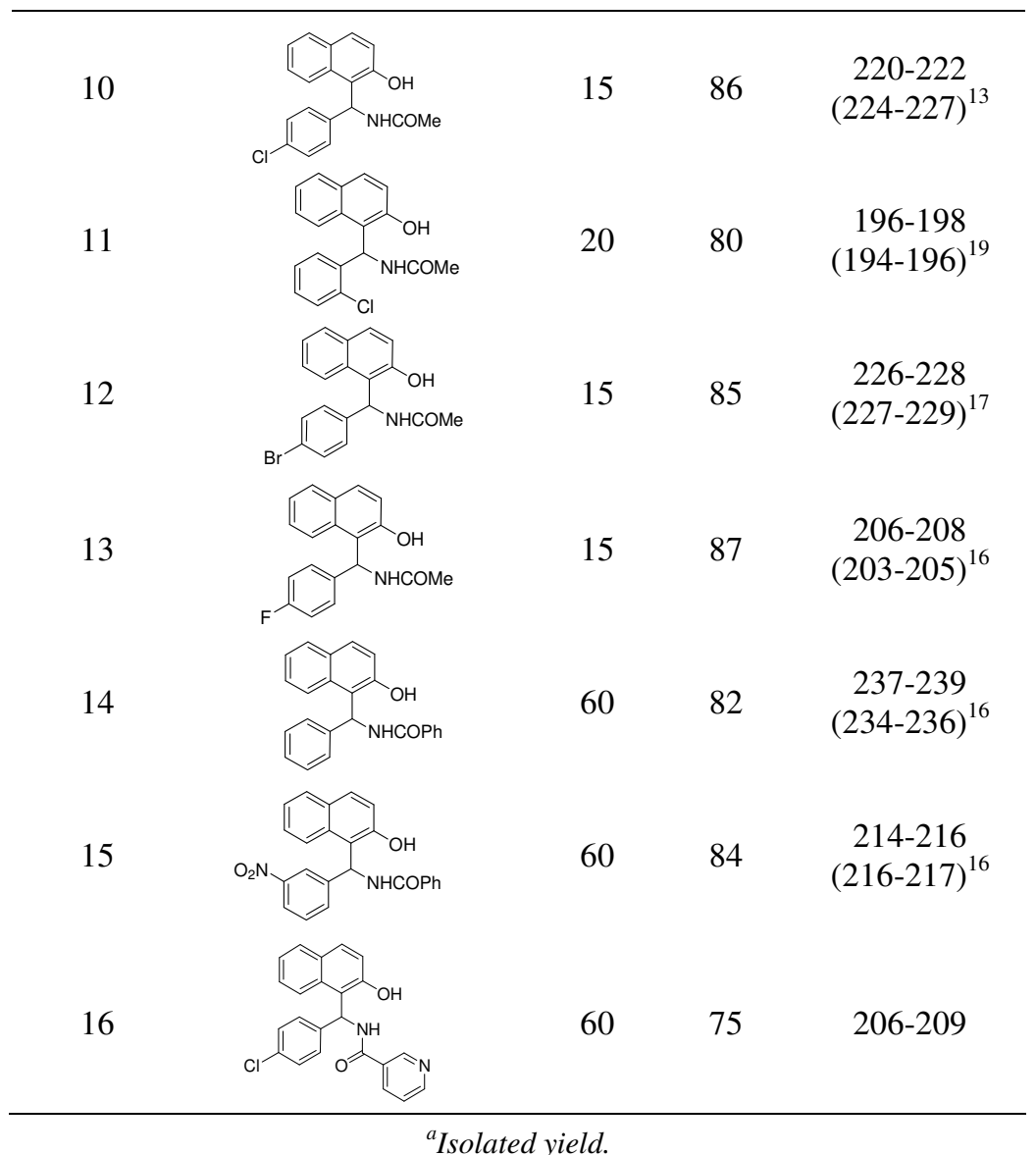

The condensation of 2-naphthol with bis-aldehydes (terephthaldehyde) and acetamide was also rapidly performed using $\mathrm{H}_{3} \mathrm{PMo}_{12} \mathrm{O}_{40} \cdot \mathrm{xH}_{2} \mathrm{O} / \mathrm{SiO}_{2}$ (Scheme 2). When 1 equivalent of 2-naphthol and 1 equivalent of the adehyde were reacted with 1.2 equivalents of acetamide using $\mathrm{H}_{3} \mathrm{PMo}_{12} \mathrm{O}_{40} \cdot \mathrm{xH}_{2} \mathrm{O} / \mathrm{SiO}_{2}$ (3.17 mol\%); after 20 min, 1-amidoalkyl-2naphthol 17 and bis-1-amidoalkyl-2-naphthol 18 were obtained in 46 and 19\%, respectively. However, the use of 2 equivalents of 2-naphthol, 1 equivalent of terephthaldehyde and 2.4 equivalents of acetamide in the presence of $\mathrm{H}_{3} \mathrm{PMo}_{12} \mathrm{O}_{40} \cdot \mathrm{xH}_{2} \mathrm{O} / \mathrm{SiO}_{2}(6.34 \mathrm{~mol} \%)$ gave compounds 17 and 18 in 16 and 75\%, correspondingly, within 30 min.

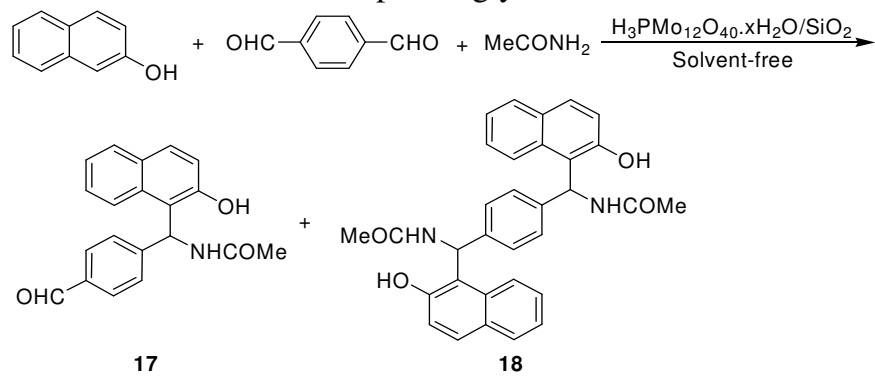

Scheme 2 
To compare the applicability and the efficiency of silica-supported $\mathrm{H}_{3} \mathrm{PMo}_{12} \mathrm{O}_{40} \cdot \mathrm{xH}_{2} \mathrm{O}$ with the reported catalysts for the synthesis of 1-amidoalkyl-2-naphthols, we have tabulated turn-over frequency $\{\mathrm{TOF}=$ yield $(\%) /[$ reaction time $(\mathrm{min}) \times \operatorname{mol} \%$ of catalyst $]\}$ of these catalysts to perform the condensation of 2-naphthol with benzaldehyde and acetamide in Table 3. As Table 3 indicates, $\mathrm{H}_{3} \mathrm{PMo}_{12} \mathrm{O}_{40} \cdot \mathrm{xH}_{2} \mathrm{O} / \mathrm{SiO}_{2}$ is superior to the previously reported catalysts in term of TOF.

Table 3. Comparison of the results of the condensation of 2-naphthol with benzaldehyde and acetamide catalyzed by $\mathrm{H}_{3} \mathrm{PMo}_{12} \mathrm{O}_{40} \cdot \mathrm{xH}_{2} \mathrm{O} / \mathrm{SiO}_{2}$ with those obtained by the recently reported catalysts.

\begin{tabular}{|c|c|c|c|c|c|}
\hline Catalyst & $\begin{array}{c}\text { Catalyst, } \\
\text { mol\% }\end{array}$ & $\begin{array}{l}\text { Time, } \\
\text { min }\end{array}$ & $\begin{array}{c}\text { Yield, } \\
\%\end{array}$ & $\begin{array}{l}\mathrm{TOF}^{\mathrm{a}} \\
\mathrm{min}^{-1}\end{array}$ & Ref. \\
\hline $\mathrm{H}_{3} \mathrm{PMo}_{12} \mathrm{O}_{40} \cdot \mathrm{xH}_{2} \mathrm{O} / \mathrm{SiO}_{2}$ & 3.17 & 15 & 91 & 1.91 & $-{ }^{b}$ \\
\hline $\mathrm{Ce}\left(\mathrm{SO}_{4}\right)_{2}$ & 100 & 2160 & 72 & 0.00033 & 13 \\
\hline Montmorillonite K10 & $0.1 \mathrm{~g}$ & 90 & 89 & - & 14 \\
\hline $\mathrm{I}_{2}$ & 5 & 330 & 85 & 0.051 & 15 \\
\hline $\mathrm{Fe}\left(\mathrm{HSO}_{4}\right)_{3}$ & 5 & 65 & 83 & 0.255 & 18 \\
\hline Sulfamic acid & 51.5 & 15 & 89 & 0.115 & 19 \\
\hline Cyanuric chloride & 10 & 10 & 91 & 0.91 & 21 \\
\hline $\mathrm{K}_{5} \mathrm{CoW}_{12} \mathrm{O}_{40} \cdot 3 \mathrm{H}_{2} \mathrm{O}$ & 1 & 120 & 90 & 0.75 & 22 \\
\hline
\end{tabular}

\section{Conclusion}

In summary, we have developed a new protocol for the synthesis of 1-aminoalkyl-2naphthols as biologically interesting compounds via the one-pot multi-components condensation of 2-naphthol, aromatic aldehydes and amides using silica-supported $\mathrm{H}_{3} \mathrm{PMo}_{12} \mathrm{O}_{40} \cdot \mathrm{xH}_{2} \mathrm{O}$ under solvent-free conditions. The advantages of this method are efficiency, generality, high yield, relatively short reaction time, cleaner reaction profile, simplicity, ease of preparation of the catalytic system, ease of product isolation, and compliance with the green chemistry protocols.

\section{Acknowledgment}

The authors thank Payame Noor University (PNU) and Persian Gulf University Research Councils for the financial support of this work.

\section{References}

1. Dingermann T, Steinhilber D and Folkers G, Molecular Biology in Medicinal Chemistry, Wiley-VCH, Weinheim, 2004.

2. Shen A Y, Tsai C T and Chen C L, Eur J Med Chem., 1999, 34, 877.

3. Damodiran M, Selvam N P and Perumal P T, Tetrahedron Lett., 2009, 50, 5474.

4. Kusakabe Y, Nagatsu J, Shibuya M, Kawaguchi O, Hirose C and Shirato S, J Antibiot., 1972, 25, 44-47.

5. Renullard S, Rebhun L I, Havic G A and Kupchan S M, Science, 1975, 189, 1002-1005.

6. Lesher G Y and Surrey A R, J Am Chem Soc., 1955, 77, 636.

7. Mosher H S, Frankel M B and Gregory M, J Am Chem Soc., 1953, 75, 5326-5328.

8. Peglion J L, Vian J, Gourment B, Despaux N, Audinot V and Millan M, Bioorg Med Chem Lett., 1997, 7, 881-886.

9. Ren H, Grady S, Gamenara D, Heinzen H, Moyna P, Croft S, Kendrick H, Yardley V and Moyna G, Bioorg Med Chem Lett., 2001, 11, 1851-1854. 
10. Benedini F, Bertolini G, Cereda R, Doná G, Gromo G, Levi S, Mizrahi J and Sala A, J Med Chem., 1995, 38, 130-136.

11. Clark R D, Caroon J M, Kluge A F, Repke D B, Roszkowski A P, Strosberg A M, Baker S, Bitter S M and Okada M D, J Med Chem., 1983, 26, 657-661.

12. Matsuoka H, Ohi N, Mihara M, Suzuki H, Miyamoto K, Maruyama N, Tsuji K, Kato N, Akimoto T, Takeda Y, Yano K and Kuroki T, J Med Chem., 1997, 40, 105-111.

13. Selvam N P and Perumal P T, Tetrahedron Lett., 2006, 47, 7481.

14. Kantevari S, Vuppalapati S V N and Nagarapu L, Catal Commun., 2007, 8, 1857.

15. Das B, Laxminarayana K, Ravikanth B and Rao B R, J Mol Catal A: Chem., 2007, 261, 180.

16. Patil S B, Singh P R, Surpur M P and Samant S D, Synth Commun., 2007, 37, 1659.

17. Shaterian H R and Yarahmadi H, ARKIVOC, 2008, 2, 105.

18. Shaterian H R, Yarahmadi H and Ghashang M, Bioorg Med Chem Lett., 2008, 18, 788.

19. Patil S B, Singh P R, Surpur M P and Samant S D, Ultrason Sonochem., 2007, 14, 515.

20. Shaterian H R, Yarahmadi H and Ghashang M, Tetrahedron, 2008, 64, 1263.

21. Mahdavinia G H and Bigdeli M A, Chin Chem Lett., 2009, 20, 383.

22. Nagarapu L, Baseeruddin M, Apuri S and Kantevari S, Catal Commun., 2007, 8, 1729.

23. Misono M, C R Acad Sci II C, 2000, 3, 471.

24. Firouzabadi H and Jafari A A, J Iran Chem Soc., 2005, 2, 85.

25. Rafiee E, Paknezhad F, Shahebrahimi S, Joshaghani M, Eavani S and Rashidzadeh S, J Mol Catal A: Chem., 2008, 282, 92.

26. Ren S, Xie Z, Cao L, Xie X, Qin G and Wang J, Catal Commun., 2009, 10, 464.

27. Rafiee E, Joshaghani M, Tork F, Fakhri A and Eavani S, J Mol Catal A: Chem., 2008, 283, 1.

28. Niknam K, Karami B, Molazadeh S and Pourkhosro A, Synth Commun., 2007, 37, 1091-1096.

29. Kumar M A, Krishna A B, Babu B H, Reddy C B and Reddy C S, Synth Commun., 2008, 38, 3456.

30. Zolfigol M A and Shiri M, Mendeleev Commun., 2005, 15, 165.

31. Azizi N and Saidi M R, Tetrahedron, 2007, 63, 888.

32. Clark J H and Rhodes C N, Clean Synthesis using Porous Inorganic Solid Catalysts and Supported Reagents, $1^{\text {st }}$ Ed., Royal Society of Chemistry, UK, 2000.

33. Tanaka K, Solvent-free Organic Synthesis, Wiley-VCH, GmbH and KGaA, Weinheim, 2004.

34. Sheldon R A and Bekkum van H, Fine Chemicals through Heterogeneous Catalysis, $1^{\text {st }}$ Ed., Wiley-VCH, Weinheim, Germany, 2001.

35. Zare A, Hasaninejad A, Beyzavi M H, Moosavi Zare A R, Khalafi-Nezhad A, Asadi F, Baramaki L, Jomhori-Angali S and Ghaleh-Golabi R, Synth Commun., 2009, 39, 139-157.

36. Hasaninejad A, Zare A, Jafari F and Moosavi-Zare A R, E- J Chem., 2009, 6, 459.

37. Zare A, Hasaninejad A, Rostami E, Moosavi-Zare A R, Merajoddin M, Arghoon A, Pishahang N and Shekouhy M, E-J Chem., 2009, 6(S1), S390.

38. Salehi P, Zolfigol M A, Shirini F and Baghbanzadeh M, Curr Org Chem., 2006, 10, 2171.

39. Zare A, Hasaninejad A, Shekouhy M and Moosavi Zare A R, Org Prep Proced Int., 2008, 40, 457.

40. Hasaninejad A, Zare A, Sharghi H and Shekouhy M, Arkivoc, 2008, 11, 64.

41. Zare A, Parhami A, Soltani Rad M N and Nejabat G R, J Iran Chem Soc., 2007, 4, 271.

42. Hasaninejad A, Zare A, Sharghi H, Shekouhy M, Khalifeh R, Salimi Beni A and Moosavi Zare A R, Can J Chem., 2007, 85, 416. 


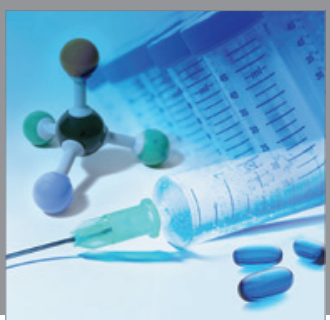

International Journal of

Medicinal Chemistry

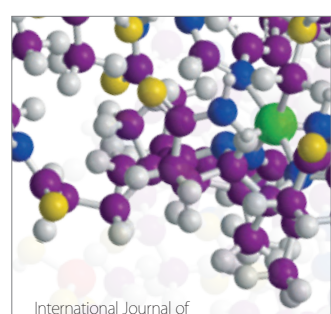

Carbohydrate Chemistry

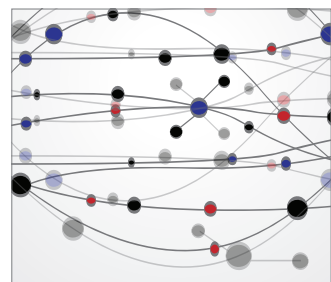

The Scientific World Journal
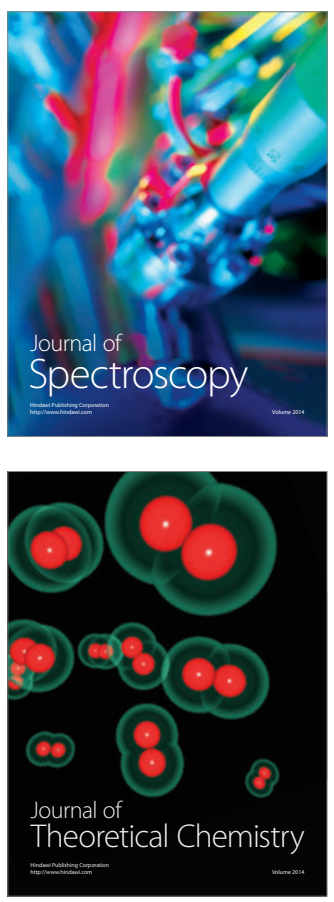
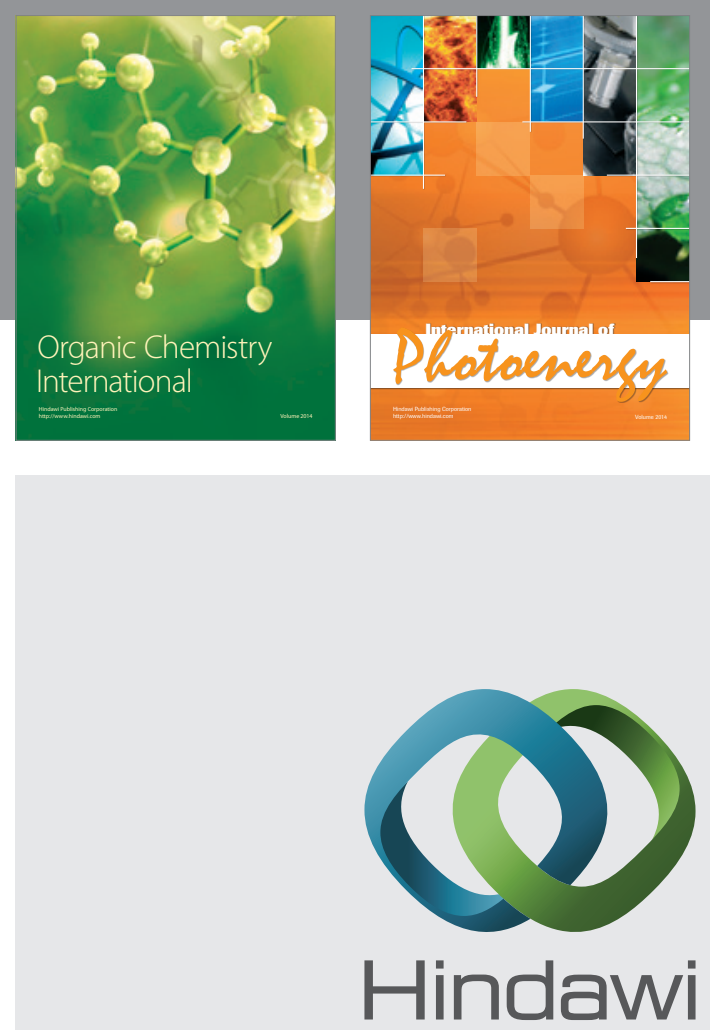

Submit your manuscripts at

http://www.hindawi.com
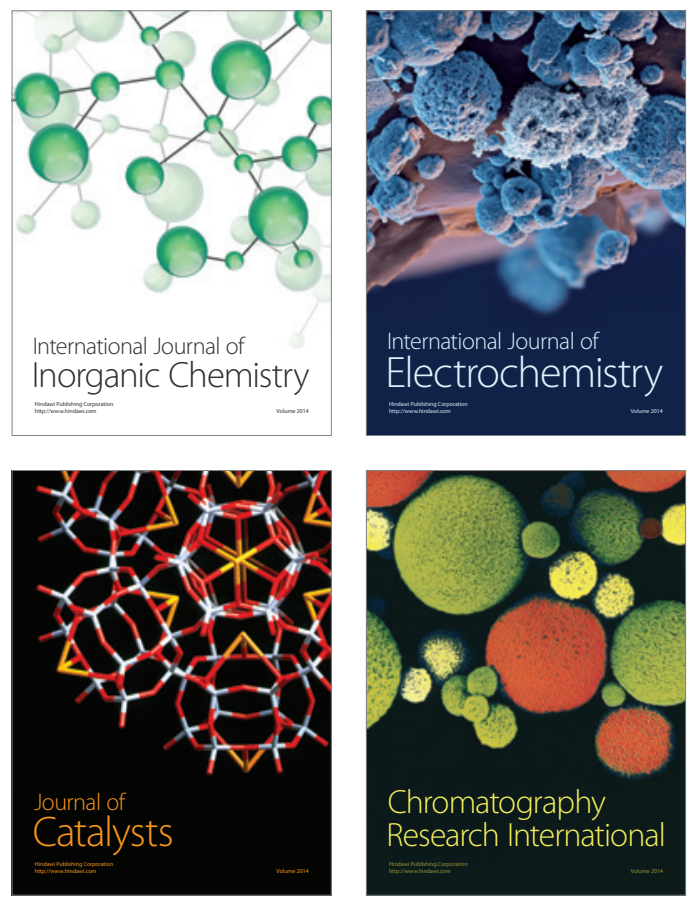
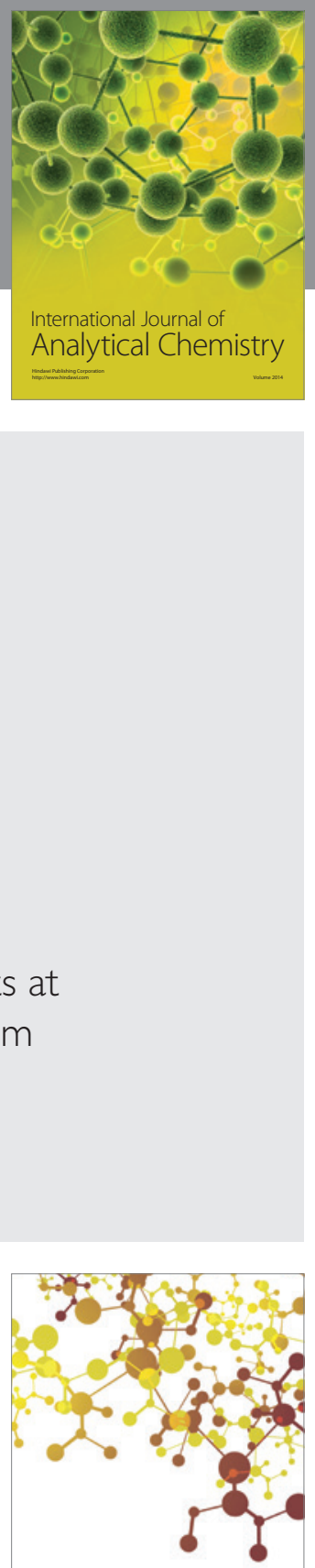

Journal of

Applied Chemistry
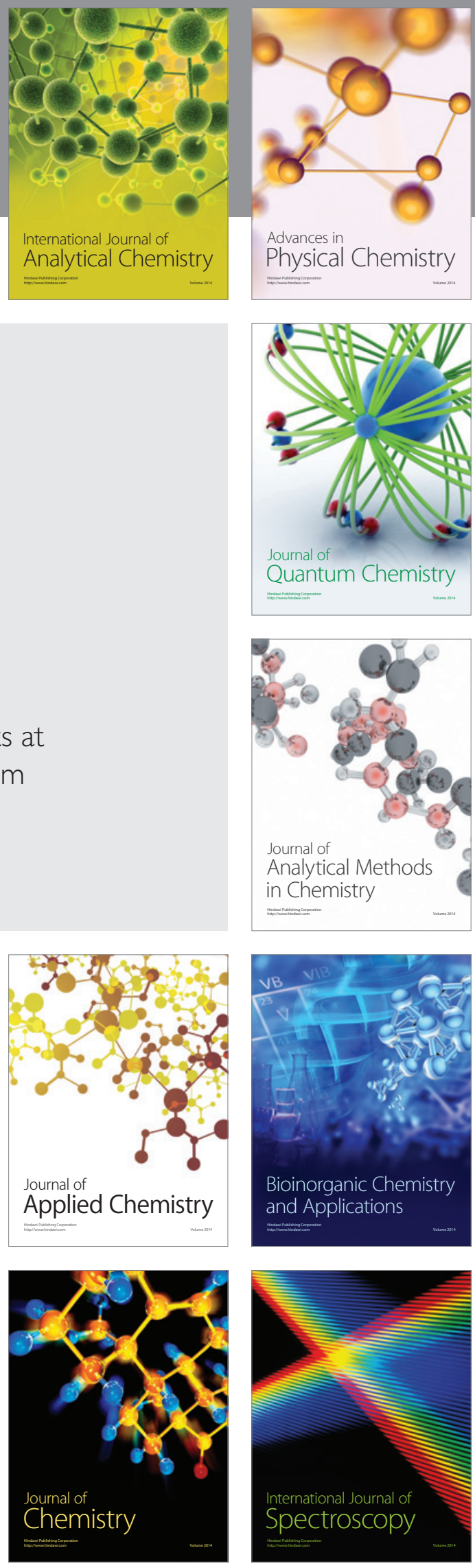